\title{
Ultrasonography and hormone profiles of persistent ovarian follicles (cysts) induced with low doses of progesterone in cattle
}

\author{
K. M. Noble, J. E. Tebble, D. Harvey and H. Dobson* \\ Department of Clinical Veterinary Science and Animal Husbandry, University of Liverpool, Leahurst, Chester High Road, \\ Neston CH64 7TE, UK
}

\begin{abstract}
The aims of this study were to expose dominant ovarian follicles at the end of the oestrous cycle to low progesterone concentrations similar to those that occur during stress, and to examine the effect of a subsequent small increase in progesterone 10 days later. Half a progesterone releasing intravaginal device (0.5 PRID) was administered to 13 heifers from day 15 of the oestrous cycle. In group $1(n=7)$, one 0.5 PRID remained in place until day 40 or until each heifer ovulated. In group $2(n=6)$, the first 0.5 PRID was removed on day 28, and replaced immediately with a second 0.5 PRID. Ultrasonography and blood collection $(10 \mathrm{ml})$ were conducted each day for 26 days from day 14 and then on alternate days. The largest follicle that emerged during the first 5 days after insertion of the initial 0.5 PRID remained $>10 \mathrm{~mm}$ in diameter for $15.3 \pm 1.7$ and $11.6 \pm 0.4$ days in groups 1 and 2, respectively. This period of dominance, during which no other follicles emerged, was closely correlated with the duration of plasma oestradiol concentrations exceeding $10 \mathrm{pg} \mathrm{ml}^{-1}$. In four heifers from group 1, the persistent follicle ovulated between days 30 and 37 (sub-group 1a; 0.5 PRID expelled). In three heifers from sub-group $1 \mathrm{~b}$ (0.5 PRID retained), the dominant follicle secreted oestradiol for $17 \pm 5$ days but remained detectable by ultrasonography for a total of $33 \pm 8$ days (range 26-52 days). Monitoring continued beyond day 40 in these animals. In group 2, the new 0.5 PRID inserted on day 28 resulted in an increase in plasma progesterone concentration of $0.9 \pm 0.3 \mathrm{ng} \mathrm{ml}^{-1}$. Simultaneously, oestradiol decreased by $10.1 \pm 3.3 \mathrm{pg} \mathrm{ml}^{-1}$, and a new follicular wave emerged 5-7 days later. In conclusion, exposure to very low concentrations of progesterone produced persistent follicles that secreted oestradiol for 17 days. This oestradiol production could be disrupted by a second increase of $0.9 \mathrm{ng} \mathrm{ml}^{-1}$ in peripheral progesterone concentration. In the absence of the second progesterone treatment, some of the persistent follicles remained detectable by ultrasonography for up to 52 days, despite cessation of oestradiol secretion.
\end{abstract}

\section{Introduction}

Variations in plasma progesterone concentrations have a profound effect on ovarian follicular function in cattle. During the oestrous cycle, follicle turnover is increased in the luteal phase and dominant follicles only mature with successful ovulation in the presence of the low peripheral progesterone concentrations in the follicular phase (Savio et al., 1990). Animals exposed in the follicular phase to either exogenous adrenocorticotrophic hormone (ACTH) or stressors such as transport show a small increase in plasma progesterone concentration, which leads to delay or inhibition of the LH surge and the formation of persistent ovarian follicles (Dobson and Smith, 1995; Dobson et al., 1999a). The

${ }^{*}$ Correspondence.

Received 30 March 2000
ACTH- or stress-induced progesterone originates from the adrenal glands (Watson and Munro, 1984).

Progesterone influences follicular growth indirectly by changing LH pulse frequency (Fortune, 1994). Previous studies have examined the effects of high concentrations of exogenous progesterone on bovine follicular growth. The doses used increased peripheral progesterone concentrations to luteal values of $3-6 \mathrm{ng} \mathrm{ml}^{-1}$. This increase exceeds the $0.5-1.0 \mathrm{ng} \mathrm{ml}^{-1}$ increase observed during the stressful stimulus of transport (Watson and Munro, 1984; Dobson et al., 1999b). Furthermore, in other studies, treatments were administered for a limited time (4-14 days) and removal of progesterone resulted in ovulation of the persistent follicle (Sirois and Fortune, 1990; Stock and Fortune, 1993; Mihm et al., 1994). Many of these other studies examined the effect of progesterone treatment on follicles emerging in the first 
follicular wave during days 1-6 of the oestrous cycle (Adams et al., 1992; Savio et al., 1993; Burke et al., 1994; Duchens et al., 1994). This population of follicles is exposed to a very different progesterone background compared with those follicles emerging during the end of the luteal phase.

The aim of the present study was to expose normal follicles at the end of the oestrous cycle to low progesterone concentrations similar to those that occur during stress to investigate the influence of progesterone alone (rather than in combination with increases in ACTH and cortisol). The additive effect of another subsequent small increase in progesterone was also examined after the progesteroneinduced persistent follicle had been present for 10 days.

\section{Materials and Methods}

\section{Animals and experimental design}

Thirteen beef crossbred heifers 1-2 years old were kept in loose housing and were fed each day with grass silage ad libitum and $0.25 \mathrm{~kg}$ barley. Each day, the heifers were tied loosely for reproductive ultrasound examination and then restrained in a crush for jugular venepuncture. Oestrous behaviour was monitored for $20 \mathrm{~min}$, three times each day. All heifers had histories of normal oestrous cycles and before the experiment oestrus was synchronized by two i.m. injections of $500 \mu \mathrm{g}$ cloprostenol (2 ml Estrumate, ScheringPlough, Uxbridge), administered 10 days apart. The day of synchronized oestrus was designated as day 0 . Reproductive ultrasound examination and jugular venepuncture were conducted throughout a control oestrous cycle (controls) and during the subsequent oestrous cycle the heifers were assigned randomly to one of two treatment groups (groups 1 and 2).

Heifers in groups 1 and 2 were treated with half a progesterone releasing intravaginal device (0.5 PRID; $0.78 \mathrm{~g}$ progesterone with oestradiol benzoate capsule removed, Sanofi, Watford). In group $1(n=7)$, the 0.5 PRID inserted on day 15 was to remain in place until each heifer ovulated or until day 40 . In group $2(n=6)$, the 0.5 PRID was inserted intravaginally on day 15 and removed on day 28 , but was immediately replaced with a new 0.5 PRID that had been soaked in water overnight. The second 0.5 PRID for group 2 remained in place until day 40 or until each heifer ovulated.

Reproductive ultrasound examination and jugular venepuncture were conducted each day from day 15 until ovulation for each heifer in groups 1 and 2. Each heifer was examined 7-10 days after ovulation to confirm the presence of a corpus luteum on the ovary ipsilateral to the assumed ovulation. Daily examinations ceased on day 40 (the planned final day of the experiment), but several animals that had not ovulated were examined at 2-3 day intervals until day 61 . On day 61, the remaining 0.5 PRIDs were removed and a final examination was performed on day 70 .

All procedures were conducted as licensed under UK Home Office regulations for experiments on living animals.

\section{Ultrasonography}

Ultrasound examination was performed using an ultrasound scanner (Aloka, BCF Technology, Livingstone) equipped with a $7.5 \mathrm{MHz}$ rectal transducer (Aloka, UST 55111, Tokyo). Each ovary was scanned in at least two planes and every follicle with an internal diameter $\geqslant 5 \mathrm{~mm}$ was identified. After freezing the image on the screen, the maximum internal diameter of each follicle was measured using the in-built electronic callipers. Each day, ovarian diagrams depicting the relative location of follicles $\geqslant 5 \mathrm{~mm}$ were made to determine patterns of growth and regression of individual follicles. New dominant follicles were recorded separately for each ovary to examine the intraovarian influence of dominant follicles.

\section{Definitions}

In all groups, the duration of the oestrous cycle was defined as the days between two successive ovulations or periods of oestrus (day 0). The day of ovulation was assumed when a follicle $>10 \mathrm{~mm}$ was observed for at least 2 days, but subsequently was not detected. At the end of the experiment when the frequency of ultrasound examinations decreased, ovulation was assumed to have occurred 4 days before an increase in peripheral progesterone concentration. Structural presence was defined as the time between the first and last appearance of a follicle with an internal diameter $\geqslant 5 \mathrm{~mm}$. Dominant phase defines the interval between the first day a follicle was $2 \mathrm{~mm}$ greater than the other follicles in the same wave and either the day preceding ovulation or the day of appearance of new follicles $\geqslant 5 \mathrm{~mm}$. The growing phase began on the day the follicle reached $\geqslant 5 \mathrm{~mm}$ and ended on the first day of the static phase. The beginning of the static phase was defined as the first day a follicle did not increase more than $1 \mathrm{~mm}$ in diameter in a subsequent 2 day period. The end of the static phase coincided with ovulation or the start of follicle regression. Growth rates were calculated by linear regression of follicle diameters throughout the growing phase.

\section{Blood samples and hormone measurement}

Blood samples were collected from the jugular vein after each ultrasound examination. Blood $(10 \mathrm{ml})$ was collected into evacuated tubes (Vacutainers; Becton-Dickinson, Meylan-Cedex) that contained 143 iu units lithium heparin as anticoagulant. Within $1 \mathrm{~h}$, the samples were centrifuged at $1000 \mathrm{~g}$ for $30 \mathrm{~min}$ at room temperature. Plasma was separated and stored at $-20^{\circ} \mathrm{C}$ until hormone analysis.

Previously characterized radioimmunoassays were used to measure plasma concentrations of cortisol and progesterone (Dobson et al., 1999b), FSH (Dobson, 1978), oestradiol (Beard et al., 1994) and LH (Alam and Dobson, 1986). The FSH assay was modified to use antiserum AFP C5288113 (1:16000) and 10000 c.p.m. labelled FSH (AFP 5679C RP-1). The standard used for the FSH assay was AFP 5679C RP-1 and NIDDK bLH B8 was used for the LH assay. For samples 
Table 1. Characteristics of the initial or subsequent dominant follicles in heifers from the control group, group 1 (original 0.5 PRID retained) and group 2 (0.5 PRID exchanged on day 28)

\begin{tabular}{|c|c|c|c|c|c|c|}
\hline & \multicolumn{5}{|c|}{$\begin{array}{l}\text { Initial dominant } \\
\text { follicles }\end{array}$} & \multirow{2}{*}{$\begin{array}{c}\begin{array}{c}\text { Subsequent dominant } \\
\text { follicles }\end{array} \\
\begin{array}{c}\text { Groups } 1 \text { and } 2 \\
(n=7)\end{array}\end{array}$} \\
\hline & $\begin{array}{l}\text { Controls } \\
(n=12)\end{array}$ & $\begin{array}{l}\text { All group } 1 \\
(n=7)\end{array}$ & $\begin{array}{l}\text { Sub-group } 1 \mathrm{a} \\
\quad(n=4)\end{array}$ & $\begin{array}{l}\text { Sub-group } 1 \mathrm{~b} \\
\quad(n=3)\end{array}$ & $\begin{array}{l}\text { Group } 2 \\
(n=5)\end{array}$ & \\
\hline Growing phase (days) & $5.0 \pm 0.5$ & $6.1 \pm 0.8$ & - & - & $5.4 \pm 1.1$ & $4.5 \pm 0.5$ \\
\hline Growth rate (mm per day) & $1.6 \pm 0.2$ & $1.4 \pm 0.2$ & - & - & $1.4 \pm 0.2$ & $2.1 \pm 0.2$ \\
\hline Static phase (days) & $0.8 \pm 0.5^{\mathrm{a}}$ & $12.5 \pm 1.9^{\mathrm{b}}$ & - & - & $11.0 \pm 1.3^{\mathrm{b}}$ & $6.4 \pm 1.8^{c}$ \\
\hline Dominant phase (days) & $3.1 \pm 0.5^{\mathrm{a}}$ & $15.3 \pm 1.7^{\text {cde }}$ & $12.0 \pm 1.2^{\mathrm{d}}$ & $17.8 \pm 2.3^{\mathrm{e}}$ & $11.6 \pm 0.4^{\mathrm{bd}}$ & $10.1 \pm 2.1^{\mathrm{d}}$ \\
\hline Maximum size $(\mathrm{mm})$ & $14.6 \pm 0.4^{\mathrm{a}}$ & $19.7 \pm 0.6^{c}$ & $20.7 \pm 0.9^{c}$ & $19.0 \pm 0.5^{c}$ & $17.3 \pm 0.6^{\mathrm{b}}$ & $16.7 \pm 1.4^{\mathrm{c}}$ \\
\hline Structural presence (days) & $5.8 \pm 0.4^{\mathrm{a}}$ & $26.4 \pm 5.1^{\mathrm{bc}}$ & $15.7 \pm 1.3^{\mathrm{b}}$ & $34.5 \pm 6.4^{c}$ & $26.0 \pm 3.0^{b c}$ & $>17.2 \pm 1.9^{\mathrm{b}}$ \\
\hline
\end{tabular}

Values are given as mean \pm SE. Group 1 is subdivided into sub-group 1a (prematurely ovulated) and sub-group $1 \mathrm{~b}$ (anovulatory).

PRID: progesterone releasing intravaginal device.

abcdeValues without a superscript in common within the same row differ significantly $(P<0.05)$.

in the range of those in the current study, intra- and interassay coefficients of variation for all assays were $<13 \%$. All samples from individual animals were measured in the same assay for each of the hormones.

\section{Statistical analysis}

Rates of growth of dominant follicles in control and treated animals were calculated by regression analysis. The linear regression lines were examined for parallelism using Student's $t$ test. The size of the follicle and hormone concentrations were $\log _{10}$ transformed and were analysed using repeated measures ANOVA; data were partitioned on the basis of time and follicle status (control or persistent). Similarly, durations of follicle presence, oestradiol production and hormone concentrations on specific days were compared using Students $t$ test after $\log _{10}$ transformation. $P<0.05$ was regarded as significant. All statistical analyses were conducted using Statsview for Apple Macintosh.

\section{Results}

In group 1, the 0.5 PRID was expelled by three heifers as revealed by examination on the day after loss of the device. The 0.5 PRIDs were not replaced. After the start of treatment, a dominant follicle emerged, persisted and then ovulated in these three heifers. These heifers formed sub-group 1a together with another heifer that retained the 0.5 PRID and ovulated the persistent follicle. In three other animals, the persistent follicle did not ovulate although the 0.5 PRID was retained, and these animals formed sub-group $1 \mathrm{~b}$. In group 2, the second 0.5 PRID remained in the vagina in all animals until removal after each heifer had ovulated, or until day 61.

\section{Effect of treatment on the duration of the oestrous cycle and follicular dynamics}

The presence of 0.5 PRID prevented return to oestrus at the normal time, and significantly increased the duration of the oestrous cycle in groups 1 and 2 compared with control oestrous cycles $(35.7 \pm 2.7$ and $56.2 \pm 1.2$ versus $21.3 \pm 0.6$ days, respectively; $P<0.001)$. Oestrous behaviour was observed in 13 of 13 control heifers, 0 of 7 group 1 heifers (despite ovulation in four heifers between days 30 and 45) and 0 of 6 group 2 heifers (despite ovulation in all heifers between days 52 and 57).

A dominant follicle emerged from a new wave of follicular growth in all animals from day 15 . This dominant follicle ovulated in 13 of 13 control heifers, 4 of 7 heifers in group 1, and 0 of 6 heifers in group 2 (follicles that did ovulate emerged after the PRID was changed).

The growing phases and growth rates of the dominant follicles were similar in all groups; however, the duration of the static phase in treatment groups 1 and 2 was more than ten times greater than in controls (Table 1). The duration of the dominant phase was greater compared with controls, and was 5.8 days greater in sub-group 1a than in sub-group 1 b (Table 1). In group 2, the dominant phase was similarly extended but was curtailed by the emergence of a new wave of follicles 5-7 days after the 0.5 PRID was changed.

In both groups 1 and 2, persistent follicles grew larger than in controls, and were present four times longer (Table 1). In sub-group $1 \mathrm{~b}$, the dominant follicle persisted for a longer period of time than recorded, because in two of three animals the dominant follicle was still present on the ovary at the end of the experiment. The dominant follicle of sub-group $1 \mathrm{~b}$ was present for at least 18 days more than in sub-group 1a and for at least 8 days more than in group 2 .

Another dominant follicle emerged in those heifers that did not ovulate at about day 30 . The duration of the growing phase, growth rates and maximum size of follicles were 
similar for all dominant follicles (Table 1); however, the duration of the static phase of the second dominant follicle was shorter than that for first dominant follicle, at a time when progesterone concentrations were lower.

Either ovary had equal chance to develop the first dominant follicle (left:right, 7:5). Excluding those animals that ovulated, there was also an unbiased emergence of the subsequent dominant follicle relative to the ovary bearing the persistent follicle (ipsilateral:contralateral, 5:3), and similarly there was no influence on the ovary to bear the next follicle that eventually ovulated (ipsilateral:contralateral, 5:3).

\section{Hormone profiles}

For all groups, the mean luteal progesterone concentrations for non-ovulating animals decreased from day 17 to day 22, at which time values were higher in groups 1 and 2 (0.5 PRID-treated heifers) than in controls $(\mathrm{P}<0.01)$. From day 22 to day 28, progesterone concentrations were similar for groups 1 and 2, but greater $(\mathrm{P}<0.05)$ than concentrations at the time of ovulation in the controls. Furthermore, the progesterone concentration was $0.37 \pm 0.15 \mathrm{ng} \mathrm{ml}^{-1}$ when the persistent follicle ovulated in sub-group 1 a heifers, but was higher $\left(1.36 \pm 0.17 \mathrm{ng} \mathrm{ml}^{-1} ; \mathrm{P}<0.05\right)$ at a similar time and follicle size in animals with persistent follicles that did not ovulate. In the latter animals, progesterone values were $0.63 \pm 0.10 \mathrm{ng} \mathrm{ml}^{-1}$ when oestradiol production by persistent follicles began to decline belatedly. In group 2 heifers, an increase in progesterone concentration of $0.9 \pm 0.3 \mathrm{ng} \mathrm{ml}^{-1}$ occurred between days 28 and 29 when the 0.5 PRID was changed (Fig. 1a).

In control cows, plasma oestradiol concentrations were high for 4 days until the day of oestrus, day 21 (Fig. 1b). In contrast, oestradiol concentrations remained $>10 \mathrm{pg} \mathrm{ml}^{-1}$ for $14 \pm 3.2$ days in the ovulating heifers of sub-group $1 \mathrm{a}$, for $17 \pm 5$ days in the presence of the non-ovulatory persistent follicles of sub-group $1 b$, and for $12 \pm 1.1$ days until the PRID was changed in group 2. In all heifers, the duration of the dominant phase was highly correlated $(\mathrm{r}=0.93, \mathrm{P}<0.001)$ with the time that plasma oestradiol concentrations exceeded $10 \mathrm{pg} \mathrm{ml}^{-1}$. However, in non-ovulating heifers of sub-group $1 b$, oestradiol concentrations were high for only half the time the persistent follicle was detectable by ultrasonography (17 \pm 5 versus $33 \pm 8$ days; $\mathrm{P}<0.05)$. The maximum mean oestradiol concentrations were similar in heifers with either ovulatory or persistent follicles (Fig. 1b).

In the treated groups, mean plasma FSH concentrations were similar to the controls from day 17 to day 28 (Fig. 1c). On day 29, the day after the 0.5 PRID was replaced, there was an increase in plasma FSH concentrations in group 2, but not in group 1. In all heifers there was an increase in FSH concentrations 2 days before the growth of each wave of follicles (Fig. 1c).

The growth of follicles in one heifer in sub-group $1 b$ (Heifer 669) was associated with a very high concentration of oestradiol (30-40 $\mathrm{pg} \mathrm{ml}^{-1}$ ) (Fig. 2). This heifer did not ovulate between day 46 and day 66 despite minimum progesterone concentrations $\left(<0.5 \mathrm{ng} \mathrm{ml}^{-1}\right)$.
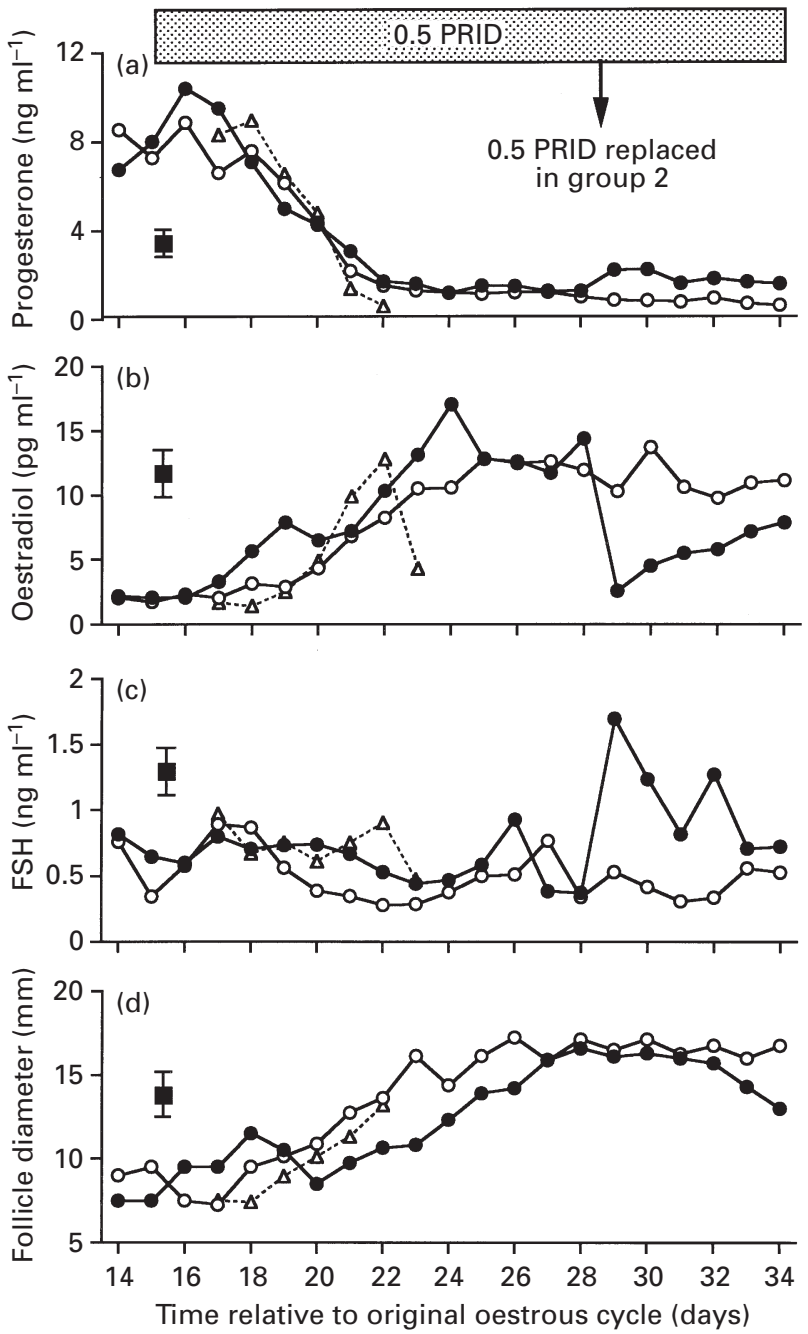

Fig. 1. Mean plasma concentration of (a) progesterone, (b) oestradiol, (c) FSH and (d) maximum internal diameter of dominant (persistent) follicles in controls $(\triangle)$, non-ovulatory sub-group $1 \mathrm{~b}$ heifers $(\bigcirc ; n=4)$ and non-ovulatory group 2 heifers $(\bullet ; n=5)$. The duration of administration of half a progesterone releasing intravaginal device (0.5 PRID) is represented by the horizontal bar, and the variance of measurement for all samples is shown for each

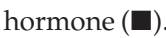

\section{Discussion}

The present study is the first to show that low concentrations of progesterone, equivalent to stress-induced concentrations, cause persistent dominant follicles with characteristics similar to those that occur spontaneously (Savio et al., 1990). These spontaneous dominant follicles secreted oestradiol for approximately 20 days but remained detectable by ultrasonography for 40-65 days. In heifers that retained a 0.5 PRID for up to 45 days, the persistent dominant follicles were associated with increased oestradiol concentrations for 18 days but were detectable by ultrasonography for up to 52 days. These characteristics are typical of persistent follicles produced by ACTH treatment or administration of high doses of progesterone and oestradiol (Dobson et al., 2000; Ward et al., 2000). This finding indicates a common outcome 

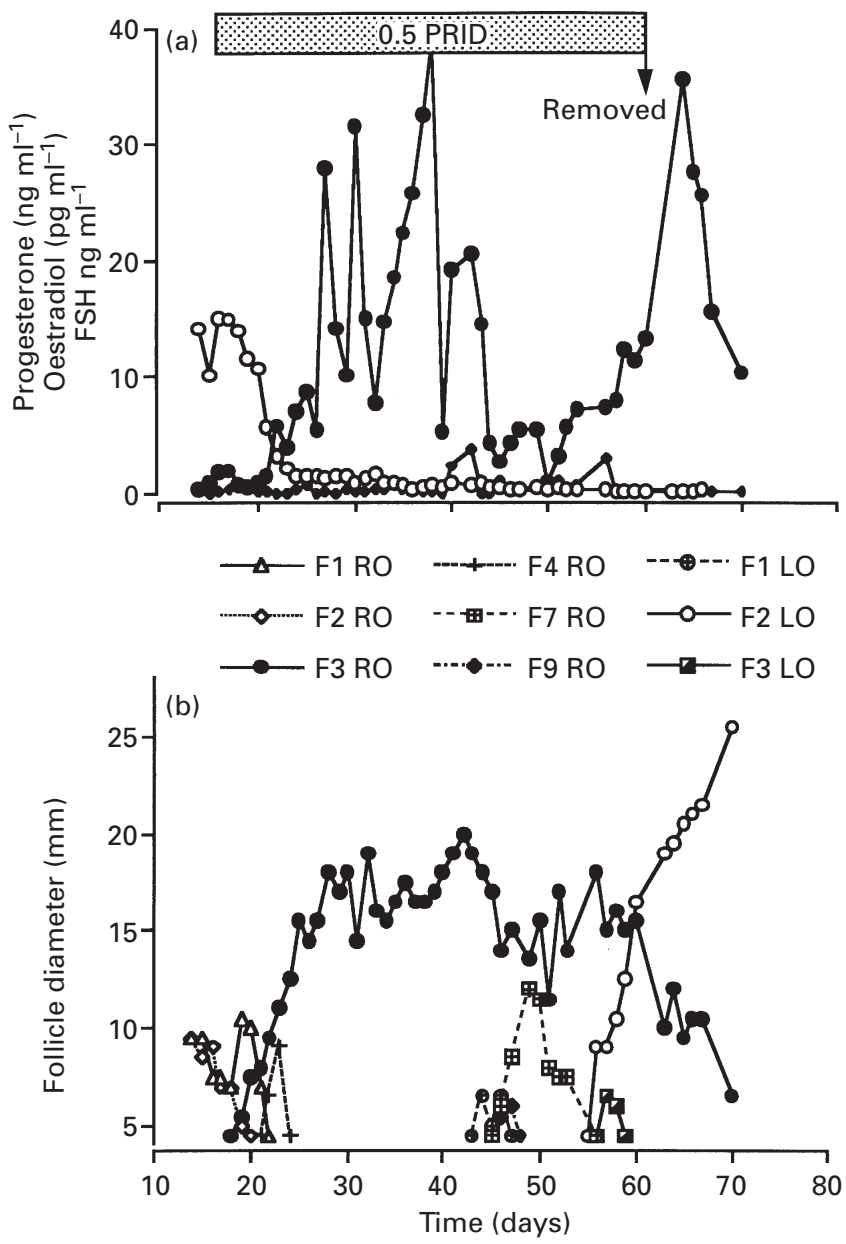

Fig. 2. Plasma concentration of (a) progesterone (ng $\left.\mathrm{ml}^{-1} ; \bigcirc\right)$, oestradiol (pg ml-1; diameters of dominant follicles $(\bullet, \bigcirc)$ and other individual follicles (other symbols) in Heifer 669 of sub-group 1b. The duration of administration of half a progesterone releasing intravaginal device (0.5 PRID) is represented by the horizontal bar. RO: right ovary; LO: left ovary.

despite the different causes. Persistent follicles induced in the present study were maintained at progesterone concentrations that were high enough to block the LH surge; ACTH-induced persistent follicles produced insufficient oestradiol to cause an LH surge, whereas treatment with high doses of steroids produced prolonged increases of oestradiol that inhibited the generation of an LH surge (Ozturk et al., 1998). Further work is required to determine whether spontaneously occurring persistent follicles share any of these aetiologies. Moreover, it remains to be established whether persistent follicles will occur after stress-induced activation of the hypothalamus-pituitary-adrenal axis in cattle.

The present study shows that oestradiol production by a persistent dominant follicle is very susceptible to small increases in progesterone concentration (an increase of $0.9 \mathrm{ng} \mathrm{ml}^{-1}$ ), presumably as a result of small changes in LH pulse frequency. When plasma progesterone is supra-basal
(1-2 ng ml-1), LH pulse frequency is high, leading to the initial development of persistent oestrogenic follicles (Stock and Fortune, 1993). Increased progesterone concentrations lead to lower LH pulse frequencies and dominant follicle atresia (Fortune, 1994). However, in the absence of increased progesterone, there may be an upper limit of approximately 20 days on the time that a follicle can continue to secrete oestradiol and, therefore, remain dominant. The reason for the onset of atresia remains unknown.

It is pertinent to consider why the persistent follicle ovulated in some heifers but not in others. Peripheral FSH, oestradiol and progesterone concentrations were similar at follicle emergence for both types of animals, in which the persistent follicle ovulated and those in which it did not, and oestradiol concentrations were the same at the equivalent time of ovulation. For heifers from sub-group 1a, in which the persistent follicle ovulated, it is probable that the low progesterone milieu permitted an LH surge, whereas higher progesterone concentrations (0.4 versus $\left.1.4 \mathrm{ng} \mathrm{ml} \mathrm{ml}^{-1}\right)$ inhibited the LH surge but permitted continuation of high frequency LH pulses. Indeed, there have been suggestions that basal $\mathrm{LH}$ concentrations are higher in animals with persistent follicles (Garverick, 1997), and LH binding is greater in persistent follicles (Kawate et al., 1990). Whether these are the causes or the effects remains to be established.

In the present study, the duration of the dominant phase was closely correlated with the time that plasma oestradiol concentration was $>10 \mathrm{pg} \mathrm{ml}^{-1}$, which supports the concept of a functionally dominant period. Loss of dominance occurred when the dominant follicle ceased oestradiol production (with or without ovulation), and plasma FSH concentration increased, resulting in the emergence of a new wave of follicles 5-7 days later. Confirmation of the presence or absence of medium-sized (5-9 $\mathrm{mm}$ ) follicles will be useful in veterinary clinical diagnosis to predict the endocrine status of large persistent follicles and will, therefore, aid selection of the most appropriate treatment (reviewed by Nanda et al., 1989).

The structural development of persistent follicles has received little attention to date. In the present study, there was no difference between the duration of the growing phase and the growth rate of the dominant follicle between control and persistent follicles, with or without subsequent ovulation. Persistence was due to an extended static phase during which the follicle gradually reached a greater maximum size compared with dominant follicles in control oestrous cycles. Knopf et al. (1989) suggested that the dominant follicle of the first follicular wave in the oestrous cycle grew at a faster rate than that of the second follicular wave due to lower plasma progesterone concentrations. However, the present study is in agreement with Sirois and Fortune (1990) and Savio et al. (1990) who suggested that there was no difference in the growth rate of follicles despite the different plasma progesterone concentrations during growth. At the other end of the follicle life-span, it is unclear why persistent follicles were present for such a long period of time, especially in the absence of oestradiol secretion. No evidence could be found to support the hypothesis that persistent follicles (oestrogenic or not) influence subsequent follicular growth in the same ovary. 
The present study provides further evidence for the importance of prior exposure to progesterone for cows to express oestrous behaviour. Lack of immediate prior exposure to luteal concentrations of progesterone is thought to be the reason why many cows do not show oestrous behaviour in association with the first postpartum ovulation. Savio et al. (1990) did not detect oestrus in most dairy cows before the first ovulation. In the present study, of nine heifers that ovulated between day 30 and day 57, only three displayed behavioural oestrus. These heifers had not been exposed to luteal concentrations of progesterone for $\geqslant 12$ days before ovulation. In all of these animals, progesterone concentrations must have been sufficiently low to allow an LH surge, and therefore ovulation, although in some heifers the 0.5 PRID remained in place. This observation concurs with the fact that most cows with naturally occurring persistent follicles are presented for clinical examination as cases of anoestrus (Farin and Estil, 1993).

In conclusion, the persistent follicles that developed in heifers that were exposed to a low dose of progesterone had similar characteristics to spontaneously occurring persistent follicles. Treatment with 0.5 PRID produced persistent follicles that either ovulated or secreted oestradiol for an average of 17 days. Oestradiol production was disrupted by an increase of $0.9 \mathrm{ng} \mathrm{ml}^{-1}$ in peripheral progesterone concentration. In the absence of ovulation, the persistent follicle remained detectable by ultrasonography for up to 52 days, despite cessation of oestradiol production.

The current study was undertaken by K. M. Noble in partial fulfillment of the requirements for the Diploma of Bovine Reproduction, University of Liverpool. The authors are grateful to the British Society for Animal Science for a vacation scholarship to D. Harvey; H. Purcell for expert technical assistance; N. Jones and his animal staff for diligent care of the animals; and to NIDDK, Bethesda and NHPP, California for gonadotrophin assay reagents.

\section{References}

Adams GP, Matteri RL and Ginther OJ (1992) Effect of progesterone on ovarian follicles, emergence of follicular waves and circulating FSH in heifers Journal of Reproduction and Fertility 96 627-634

Alam MGS and Dobson H (1986) Effect of various veterinary procedures on plasma concentrations of cortisol, luteinizing hormone and prostaglandin $\mathrm{F}$ metabolite in the cow Veterinary Record 118 7-10

Beard AP, Hunter MG and Lamming GE (1994) Quantitive control of oxytocin-induced PGF $(2 \alpha)$ release by progesterone and oestradiol in ewes Journal of Reproduction and Fertility 100 143-150

Burke CR, Mihm M, MacMillan KL and Roche JF (1994) Some effects of prematurely elevated concentrations of progesterone on luteal and follicular characteristics during the oestrous cycle in heifers Animal Reproduction Science 35 27-39

Dobson H (1978) Radioimmunoassay of FSH in the plasma of post-partum dairy cows Journal of Reproduction and Fertility 52 45-49

Dobson H and Smith RF (1995) Stress and reproduction in farm animals Journal of Reproduction and Fertility Supplement 49 451-461

Dobson H, Tebble JE, Phogat PB and Smith RF (1999a) Effect of transport on pulsatile and surge secretion of $\mathrm{LH}$ in ewes in the breeding season Journal of Reproduction and Fertility 116 1-8

Dobson H, Tebble JE, Ozturk M and Smith RF (1999b) Effect of transport on pulsatile LH release in ovariectomized ewes in different seasons of the year Journal of Reproduction and Fertility 117 213-222

Dobson H, Ribadu AY, Noble KM, Tebble JE and Ward WR (2000) Ultrasonography and hormone profiles of ACTH-induced persistent follicles (cysts) in cattle Journal of Reproduction and Fertility $120405-410$

Duchens M, Forsberg M, Gustafsson H, Edqvist LE and RodriquezMartinez H (1994) Endocrinology of heifers induced to estrus asynchrony by supra-basal plasma progesterone levels Theriogenology 42 1159-1163

Farin PW and Estil CT (1993) Infertility due to abnormalities of the ovaries in cattle. In Veterinary Clinics of North America Food Animal Practice 92 pp 291-299 Ed. R. Savitz. WB Saunders Company, Philadelphia

Fortune JE (1994) Ovarian follicular growth and development in mammals Biology of Reproduction $\mathbf{5 0} 225-232$

Gaverick HA (1997) Ovarian follicular cysts in cattle Journal of Dairy Science 80 995-1004

Kawate N, Inaba T and Mori J (1990) A quantitative comparison in the bovine of steroids and gonadotrophin receptors in follicular and luteal cysts Animal Reproduction Science 23 273-281

Knopf L, Kastelic JP, Schallenberger E and Ginther OJ (1989) Ovarian follicular dynamics in heifers: test of two-wave hypothesis by ultrasonically monitoring individual follicles Domestic Animal Endocrinology 6 111-119

Mihm M, Baguisi A, Boland MP and Roche JF (1994) Association between duration of dominance of the ovulatory follicle and pregnancy rate in cattle Journal of Reproduction and Fertility 102 123-130

Nanda AS, Ward WR and Dobson H (1989) Treatment of cystic ovarian disease in cattle - an update Veterinary Bulletin 59 537-556

Ozturk M, Smith RF and Dobson H (1998) Effect of prolonged exposure to oestradiol on subsequent LH secretion in ewes Journal of Reproduction and Fertility 114 1-9

Savio JD, Boland MP, Hynes N and Roche JF (1990) Resumption of follicular activity in the early post-partum period of dairy cows Journal of Reproduction and Fertility 88 569-579

Savio JD, Thatcher WW, Morris GR, Entwistle K, Drost M and Mattiacci MR (1993) Effects of induction of low plasma progesterone concentrations with a PRID on follicular turnover and fertility in cattle Journal of Reproduction and Fertility $9877-84$

Sirois J and Fortune JE (1990) Lengthening the bovine estrous cycle with low levels of exogenous progesterone: a model for studying ovarian follicular dominance Endocrinology 127 916-925

Stock AE and Fortune JE (1993) Ovarian follicular dominance in cattle: relationship between prolonged growth of the ovulatory follicle and endocrine parameters Endocrinology 132 1108-1114

Ward WR, Ribadu AY, Harvey D and Dobson H (2000) Ultrasound and hormone profiles of normal and abnormal ovarian follicles formed in cattle after treatment with high doses of progesterone and oestradiol Animal Science 71 577-584

Watson ED and Munro CD (1984) Adrenal progesterone production in the cow British Veterinary Journal 140 300-306 